\title{
RECEITA DO TURISMO RECEPTIVO NOS PAÍSES LATINO-AMERICANOS E NO CARIBE
}

\author{
Beatriz Helena Gelas Lage ${ }^{1}$
Paulo César Milone
}

\begin{abstract}
RESUMO: O presente trabalho tem como objetivo principal analisar a importância do turismo receptivo na economia de países selecionados da América Latina e do Caribe. Compara a receita de divisas gerada pelas atividades turísticas em cada um destes países com a de paises líderes do turismo mundial. Propõe que um melhor conhecimento da realidade deve ser aproveitado no planejamento de futuras políticas de expansão do turismo na regiảo latino-americana e no Caribe, como um elemento de contribuição valiosa para os processos de desenvolvimento econômico e social destes paises.
\end{abstract}

PALAVRAS-CHAVE: Turismo receptivo; receita; América Latina; Caribe.

ABSTRACT: The present paper has as its major objective to analyze the importance of the receptive tourism in the economies of selected countries in Latin America and the Caribbean. It compares the revenues generated by the tourist activities in these countries, with the revenue of top countries in world tourism. It suggests that the best knowledge of the reality must be used in the tourism expansion planning processes in order to act as an auxiliary force in the

1 Professora Associada do Departamento de Relações Públicas, Propaganda e Turismo da ECA-USP. Professora do Programa de Pós-Graduação em Integração da América Latina, PROLAM-USP.

End. para corresp.: Escola de Comunicações e Artes da USP - Departamento de Relações Públicas, Propaganda e Turismo - Cidade Universitária "Armando de Salles Oliveira" - Av. Prof. Lúcio Martins Rodrigues, 443 - Bloco B - Butantã - 05508-900 - São Paulo - SP - Brasil.

2 Professor Associado do Departamento de Economia da FEA-USP. Professor do Programa de Pós-Graduação em Integração da América Latina, PROLAM-USP. End. para corresp.: Faculdade de Economia, Administração e Contabilidade da USP - Cidade Universitária "Armando de Salles Oliveira" - Av. Prof. Luciano Gualberto, 908 - Butantã - 05508-900 - São Paulo - SP - Brasil. 
economic and social development of the Latin America and Caribbean countries.

KEY WORDS: Receptive tourism; revenue; Latin American Caribbean.

\section{DEFINIÇÕES E MAGNITUDE DO TURISMO}

Não é fácil definir turismo, nem sequer existe uma definição que seja geralmente aceita por todos os profissionais da área. A Organização Mundial do Turismo, OMT, adota o conceito que descreve o turista como um indivíduo que pernoita fora de sua residência habitual durante uma ou mais noites. Os viajantes que cruzam uma fronteira são os turistas internacionais; e, os que não o fazem são considerados turistas nacionais. Existem outras definições de natureza mais complexa, como por exemplo a conceituação de um economista sobre a indústria turística, que é distinta daquela que é feita por um sociólogo ou por um planejador urbano.

Para a grande maioria o turismo é representado por um sistema de serviços que interrelaciona as pessoas através da utilização de transporte e de comunicação para diversos destinos, onde se oferecem serviços especiais, tais como: alojamentos, alimentação e outras atrações básicas. A meta do turismo é otimizar benefícios nas áreas econômicas, sociais e ambientais. Para que o turismo tenha êxito é necessário que a região ou o país receptor se comprometa a oferecer hospitalidade. A indústria turística anfitriã deve apresentar sua cultura de maneira espontânea e demonstrar amizade e preocupação com a saúde, comodidade, segurança e a satisfação geral de seus hóspedes (WILLIAMS, 1988)

Em 1989, uma firma norte-americana de consultores econômicos divulgou alguns dados e estimativas confiáveis sobre o tamanho e o impacto da indústria turística. Dos resultados mais relevantes destacam-se:

a) o turismo é a maior indústria do mundo empregando mais de 101 milhões de pessoas, ou seja, 1 de cada 16 trabalhadores da força de trabalho mundial exerce a sua atividade profissional na indústria turística; b) em quase todos os países do mundo o turismo está situado entre as duas ou três primeiras indústrias;

c) o emprego, o investimento, a produção e o valor da produção agregada do turismo supera ao de grandes indústrias, como por exemplo: a siderúrgica, a automobilística, a têxtil e a eletronica em muitos países;

d) nos países desenvolvidos os consumidores gastam tanto em viagem e turismo como em vestuário e em saúde;

e) as empresas gastam tanto em viagens quanto em publicidade ( $\mathrm{FOO}$ TE \& HAWKINS, 1990).

Quando se considera a evolução futura de uma economia e o seu desenvolvimento industrial, não se deve ignorar a indústria de viagens e turismo. Essa indústria gera uma receita de cerca de 3 trilhões de dólares por ano, originada por um movimento físico de aproximadamente 450 milhões de viagens internacionais.

\section{TURISMO RECEPTIVO E EMISSIVO}

O turismo enquanto exportador de serviços, gera divisas como qualquer outra mercadoria ou serviço que seja exportado. Porém, nem toda atividade turística produz divisas. Existe uma parte que, pelo contrário, gasta divisas porque se comporta como importadora de serviços; e, outra que nem produz nem gasta porque não realiza transações internacionais. A parte que exporta é chamada de "turismo receptivo", a parte que importa serviços turísticos é conhecida como "turismo emissivo"; e, a parte restante é identificada como "turismo doméstico" ou "turismo interno".

O turismo interno tem muita importância econòmica porque cria empregos, serviços e receitas para o mercado interno de um país, mas para efeito deste trabalho não será analisado, especialmente pela escassez de informações nesta área. Assim sendo, este estudo limitarse-á a analisar comparativamente o papel do turismo receptivo na economia de países selecionados da América Latina e Caribe. 
A parte mais relevante das atividades turísticas em termos de definir sua importância relativa na economia dos países é a receptiva, ou seja, a exportadora. Ainda, faz-se necessário um esclarecimento acerca do que se exporta e do que se importa no turismo. Nesta atividade não se negociam bens nem atrativos, somente serviços tais como: alojamentos, transportes, alimentação e outros. Todo o viajante tem como objetivo principal de sua viagem alcançar a diversão, o prazer etc.; porém, isto não se vende nem se compra. Necessita de uma série de serviços para que este objetivo seja atingido. E, é em termos destes serviços que se refere a compra e a venda, isto é, a importação e a exportação do turismo.

\section{TURISMO RECEPTIVO - A RECEITA DOS PAÍSES LATINO-AMERICANOS E DO CARIBE}

As informações disponíveis e utilizadas para analisar o comportamento da receita turística dos países latino-americanos e do Caribe selecionados, para o período de 1970 a 1991, foram obtidas nas publicações anuais do Fundo Monetário Internacional sobre os Balanços de Pagamentos dos países que possuem estatísticas comparáveis internacionalmente.

Os dados de receita derivada do turismo receptivo, isto é, da entrada de divisas proveniente dos fluxos de turistas estrangeiros nos países em estudo são relativos ao item Viagens da conta de Serviços dos respectivos Balanços de Pagamentos. Estas estatísticas apresentam problemas de medição e, via de regra, a verdadeira receita gerada pelo turismo receptivo está subestimada; porém, constituem a única fonte de informação de que se dispõe para este tipo de estudo comparativo internacional e, com certeza estas informações oficiais estão diretamente correlacionadas com os valores totais das divisas que entram nos países através das atividades turísticas e, também, apresentam as mesmas tendências de comportamento ao longo do período analisado.

Os países da América Latina e do Caribe foram selecionados segundo critérios de importância de suas atividades turísticas de acordo com a existência de dotações de recursos naturais, das ofertas de bens e serviços turísticos, da distância geográfica para com os Estados Unidos e da formação do mercado do Cone Sul, o Mercosul. Estes países em particular sofrem de forma acentuada a influência das instabilidades políticas e econômicas do tipo: golpes militares e mudanças de regimes políticos freqüentes, inflação extremamente elevada, desemprego crescente, dívidas interna e externa enormes, expansão da produção e consumo de drogas, e empobrecimento contínuo de uma parcela cada vez maior da população destes países. Todos estes fatos que se observam no período analisado atuam negativamente sobre as possibilidades potenciais destes países receberem os fluxos de turistas estrangeiros e só começam a apresentar os primeiros sinais de melhoria a partir da segunda metade dos anos oitenta, como por exemplo no caso do México com os efeitos iniciais de seu plano de estabilização econômica (UNITED NATIONS, 1990).

Na Tabela 1 são apresentados os dados relativos à receita de divisas geradas pelo turismo receptivo, para o período de 1970 a 1991 , expressa em milhões de dólares. Estas informações indicam uma tendência de aumento das receitas turísticas em todos os países. Durante a década de setenta observa-se que o México reina absoluto com uma receita da ordem de 3,2 bilhões de dólares em 1979, representando um montante superior à soma das divisas geradas pelos demais paises.

Nos anos oitenta verifica-se o crescimento da região do Caribe, representada pelas Bahamas, Jamaica e Barbados que representam aproximadamente $50 \%$ das receitas geradas pelo turismo mexicano no biênio 1990-1991. Para o crescimento do turismo nestes países o fato mais relevante tem sido a possibilidade de receberem em seus territóriosum número elevado de turistas americanos. Destaca-se, ainda, que o México com a crise financeira de 1982 e o seu desequilíbrio econômico interno apresenta como conseqüência uma queda acentuada na sua receita turística e só começa a reagir mais vigorosamente a partir de 1987, para atingir níveis superiores a 1981 somente no início dos anos noventa.

$\mathrm{Na}$ Venezuela, Colômbia, e em especial Peru crescem as receitas turisticas de acordo com uma tendência semelhante e menos acentuada no período, mantendo as suas posições relativas. Deve-se considerar para estes países a existência de fortes influências negativas sobre o turismo receptivo derivadas das intensas e contínuas crises de natureza política, econônica e social por eles enfrentadas ao longo de todo o período analisado. O Chile, por seu lado, com marcantes resultados econômicos obtidos na década dos oitenta apresenta uma elevação significante nas suas receitas turísticas de 1989 a 1991. 
TABELA 1 - RECEITA DO TURISMO RECEPTIVO - AMÉRICA LATINA E CARIBE (milhōes de dólares)

\begin{tabular}{|c|c|c|c|c|c|c|c|c|c|c|c|}
\hline 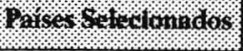 & 100 & $10 \%$ & $108 \%$ & 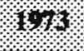 & 1978 & $106 \%$ & $1 \% 6$ & $19 \%$ & (1) & $10 \%$ & 1980 \\
\hline Argentina & 74 & 92 & 73 & 73 & 91 & 127 & 156 & 182 & 224 & 207 & 264 \\
\hline Bahamas & - & - & - & 253 & 273 & 258 & 314 & 349 & 396 & 435 & 457 \\
\hline Barbados & 40 & 52 & 58 & 59 & 63 & 64 & 72 & 95 & 110 & 160 & 194 \\
\hline Brasil & 30 & 36 & 35 & 49 & 55 & 58 & 49 & 47 & 54 & 58 & 97 \\
\hline Chile & 50 & 56 & 35 & 31 & 63 & 68 & 75 & 70 & 87 & 116 & 134 \\
\hline Colômbia & 54 & 69 & 66 & 72 & 106 & 135 & 163 & 210 & 248 & 327 & 367 \\
\hline Jamaica & 96 & 109 & 124 & 107 & 111 & 106 & 92 & 62 & 117 & 151 & 185 \\
\hline México & 1171 & 1313 & 1375 & 1503 & 1710 & 1788 & 1934 & 1816 & 2561 & 3238 & 4030 \\
\hline Paraguai & 14 & 15 & 10 & 10 & 10 & 9 & 12 & 30 & 32 & 54 & 70 \\
\hline Peru & 52 & 49 & 55 & 58 & 80 & 75 & 86 & 96 & 113 & 146 & 225 \\
\hline Uruguai & 43 & 40 & 41 & 36 & 37 & 81 & 59 & 154 & 110 & 208 & 229 \\
\hline Venezuela & 50 & 61 & 67 & 100 & 145 & 148 & 196 & 243 & 164 & 138 & 187 \\
\hline
\end{tabular}

Fonte: International Monetary Fund. Balance of Payments Yearbook. (Vários anos).

TABELA 1 (Continuą̧ão) - RECEITA DO TURISMO RECEPTIVO - AMÉRICA LATINA E CARIBE (milhões de dólares)

\begin{tabular}{|c|c|c|c|c|c|c|c|c|c|c|c|}
\hline 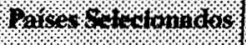 & 1481 & $100 \%$ & $1 \%$ & 154 & 1085 & $1 \%$ & $1 \%$ & 196 & $108 \%$ & $1 \% \%$ & 1041 \\
\hline Argentina & 350 & 553 & 423 & 429 & 523 & 562 & 615 & 634 & 790 & 903 & 783 \\
\hline Bahamas & 539 & 581 & 706 & 764 & 990 & 1100 & 1170 & 1144 & 1278 & 1264 & 1222 \\
\hline Barbados & 223 & 229 & 237 & - & 311 & 326 & 381 & 460 & 529 & 500 & 461 \\
\hline Brasil & 200 & 60 & 36 & 64 & 66 & 85 & 102 & 117 & 1224 & 1383 & - \\
\hline Chile & 170 & 113 & 89 & 126 & 123 & 183 & 185 & 202 & 395 & 509 & 684 \\
\hline Colômbia & 371 & 438 & 220 & 293 & 192 & 418 & 349 & 461 & 335 & 522 & 491 \\
\hline Jamaica & 241 & 305 & 374 & 413 & 407 & 516 & 595 & 527 & 593 & 740 & 764 \\
\hline México & 5382 & 2387 & 2551 & 3198 & 2900 & 2987 & 3498 & 4000 & 4766 & 5467 & 5934 \\
\hline Paraguai & 68 & 53 & 46 & 94 & 105 & 148 & 121 & 114 & 127 & 128 & 165 \\
\hline Peru & 223 & 227 & 197 & 204 & 300 & 324 & 315 & 409 & 362 & 351 & 263 \\
\hline Uruguai & 240 & 96 & 84 & 205 & 235 & 258 & 208 & 203 & 228 & 238 & 333 \\
\hline Venezuela & 159 & 280 & 290 & 349 & 416 & 444 & 416 & 291 & 389 & 496 & 419 \\
\hline
\end{tabular}

Fonte: International Monetary Fund. Balance of Pcyments Yearbook. (Vários anos). 
Com relação aos países que constituem o recente mercado comum do Cone Sul, o Mercosul, observa-se que a Argentina lidera de 1970 a 1988 a geração de receitas turísticas, seguida do Brasil, do Uruguai e do Paraguai que apresenta a pior performan os países analisados.

O Brasil, de 1989 em diante, passa a disputar com as Bahamas o segundo lugar em termos de geração de receitas turísticas. Para o caso brasileiro, como existem fortes discrepâncias de informações sobre as suas receitas turísticas conforme a fonte estatística utilizada e para o qual se dispõem de dados do Banco Central, da EMBRATUR e do Fundo Monetário Internacional, apresenta-se no item 5 deste trabalho uma análise específica sobre a real situação de seu turismo receptivo (LAGE, 1989).

TABELA 2 - RECEITA DO TURISMO RECEPTIVO:

AMERICA LATINA E CARIBE (milhões de dólares)

\begin{tabular}{|c|c|c|c|c|c|c|}
\hline \multirow{2}{*}{$x_{1}$} & \multicolumn{6}{|c|}{ Medras dos dinos. } \\
\hline & 1501019 & $1180.198 \%$ & $10 \% 01101$ & 1983.1085 & 1081,1986 & 10841901 \\
\hline Argentina & 110 & 514 & 843 & 458 & 473 & 655 \\
\hline Bahamas & 325 & 873 & 1243 & 820 & 780 & 1116 \\
\hline Barbados & 77 & 321 & 481 & 274 & 265 & 424 \\
\hline Brasil & 47 & 205 & 1383 & 55 & 85 & 434 \\
\hline Chile & 65 & 172 & 596 & 113 & 134 & 301 \\
\hline Colômbia & 145 & 344 & 506 & 235 & 322 & 383 \\
\hline Jamaica & 107 & 416 & 752 & 398 & 376 & 569 \\
\hline México & 1841 & 3860 & 5700 & 2883 & 3234 & 4094 \\
\hline Paraguai & 20 & 95 & 146 & 82 & 86 & 125 \\
\hline Penu & 71 & 279 & 307 & 234 & 246 & 316 \\
\hline Uruguai & 81 & 199 & 285 & 175 & 186 & 238 \\
\hline Venezuela & 131 & 322 & 457 & 352 & 323 & 402 \\
\hline
\end{tabular}

Fonte: Dados da Tabela 1.
$\mathrm{Na}$ Tabela 2 apresentam-se os dados da receita turística por médias para os periodos indicados. Observa-se a tendência de elevação nítida das divisas turísticas entre as décadas de setenta e de oitenta e o início dos anos noventa. Ao se comparar os valores das médias dos anos oitenta com a dos períodos de 1983 a 1985 e de 1981 a 1986 vê-se a influência negativa da primeira metade e do início da segunda metade dos anos oitenta ligada à crise financeira internacional de 1982.

A recuperação da economia mundial e os seus reflexos sobre o turismo internacional se fazem sentir ao analisar-se as médias das receitas para o período de 1984 a 1991 e, mais recentemente, para o período de 1990 a 1991, que se apresentam com valores significativamente mais elevados do que os dos demais períodos.

A seguir analisa-se a situação do turismo receptivo desses países da América Latina e do Caribe comparativamente com a de alguns países líderes do turismo mundial.

\section{RECEITA TURÍSTICA EM PAÍSES DA AMÉRICA DO NORTE, EUROPA E ÁSIA}

Nas Tabelas 3 e 4 são apresentadas as receitas turísticas de alguns países selecionados da América do Norte, Europa e Ásia. A idéia é comparar a performance desses países líderes do turismo mundial com a dos países analisados na América Latina e no Caribe.

Verifica-se dos dados da Tabela 3 que a tendência da receita do turismo receptivo para os países selecionados durante o período de 1970 a 1991 é fortemente crescente, com destaque especial para os Estados Unidos, França, Itália e Espanha que dominam o turismo mundial.

Na Tabela 4 são apresentadas as médias por períodos e observase o aumento acentuado das receitas do turismo ao longo das décadas de setenta e de oitenta, e em particular nos anos de 1990 e 1991 que parecem indicar para a década de noventa um marcante desenvolvimento do turismo internacional.

Da mesma forma que foi observada para os países latino-americanos e e para o Caribe, o período de 1982 a 1986 representa também uma desaceleração nas atividades turísticas desses países líderes do turismo que se reflete nos resultados das médias para os períodos de 
TABELA 3 - RECEITA DO TURISMO RECEPTIVO - AMÉriCA DO NORTE, EUROPA, ÁSIA (milhōes de dólares)

\begin{tabular}{|c|c|c|c|c|c|c|c|c|c|c|c|}
\hline 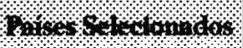 & 10 & 10 & $10 \%$ & 183 & $1.1 \%$ & $10 \%$ & $4 \%$ & $101 \%$ & 14 & $10 \%$ & 10 \\
\hline Alemanha Ocid. & 1325 & 1535 & 1810 & 2070 & 2060 & 2430 & 2860 & 3410 & 3873 & 4356 & 4815 \\
\hline Austria & 999 & 1275 & 550 & 1891 & 1916 & 2291 & 2721 & 3216 & 3765 & 4337 & 4971 \\
\hline Canadá & 1162 & 1228 & 1147 & 1202 & 1444 & 1469 & 1707 & 1627 & 1660 & 1912 & 2198 \\
\hline Espanha & 1681 & 2048 & 2305 & 2730 & 2648 & 2860 & 2672 & 3417 & 4359 & 5010 & 5335 \\
\hline Estados Unidos & 2331 & 2526 & 2600 & 2870 & 3350 & 3873 & 4970 & 5270 & 5739 & 6533 & 8129 \\
\hline França & 1318 & 1583 & 1794 & 2011 & 2156 & 2774 & 3089 & 3758 & 4738 & 5279 & 6333 \\
\hline Grécia & 194 & 305 & 362 & 432 & 363 & 516 & 715 & 839 & 1054 & 1284 & 1328 \\
\hline Holanda & 429 & 591 & 687 & 814 & 852 & 912 & 921 & 951 & 1000 & 1049 & 1279 \\
\hline Inglaterra & 1037 & 1180 & 1318 & 1490 & 1753 & 2207 & 2723 & 3515 & 3831 & 4641 & 5302 \\
\hline Itália & 1639 & 1882 & 2207 & 2275 & 2219 & 2695 & 2755 & 4073 & 5019 & 6361 & 6851 \\
\hline Japão & 232 & 172 & 180 & 170 & 200 & 210 & 270 & 360 & 374 & 426 & 426 \\
\hline Portugal & - & - & 385 & 461 & 427 & 296 & 283 & 345 & 468 & 727 & 880 \\
\hline
\end{tabular}

Fonte: International Monetary Fund. Balance of Payments Yearbook. (Vários anos).

TABELA 3 (Cont.) - RECEITA DO TURISMO RECEPTIVO - AMÉRICA DO NORTE, EUROPA, ÁSIA (milhões de dólares)

\begin{tabular}{|c|c|c|c|c|c|c|c|c|c|c|c|}
\hline 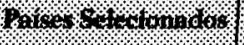 & 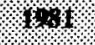 & $10 \%$ & 143 & 14\% & 10.6 & $10 \%$ & 4 & $898 \%$ & $14 \%$ & $10 \%$ & $101 \%$ \\
\hline Alemanha Ocid. & 4945 & 4888 & 5087 & 5339 & 4815 & 6657 & 7677 & 8263 & 8527 & 10706 & 10527 \\
\hline Áustria & 4822 & 5047 & 4924 & 4376 & 5088 & 6969 & 8826 & 10075 & 10715 & 13415 & 12585 \\
\hline Canadá & 2692 & 2733 & 2929 & 3318 & 3668 & 4566 & 4755 & 5627 & 6109 & 6664 & 6813 \\
\hline Espanha & 5746 & 6482 & 6412 & 7572 & 8148 & 12051 & 14717 & 16570 & 16200 & 18584 & 19010 \\
\hline Estados Unidos & 10980 & 11221 & 10668 & 11107 & 17680 & 20270 & 23370 & 28440 & 36570 & 43420 & 48760 \\
\hline França & 6117 & 6308 & 6727 & 7409 & 8027 & 9757 & 11859 & 13717 & 16200 & 20270 & 21197 \\
\hline Grécia & 1620 & 1392 & 1106 & 1288 & 1428 & 1834 & 2268 & 2396 & 1976 & 2587 & 2566 \\
\hline Holanda & 1391 & 1400 & 1376 & 1499 & 1685 & 2245 & 2708 & 2888 & 3049 & 3636 & 4046 \\
\hline Inglaterra & 5015 & 5015 & 5191 & 5393 & 7161 & 8173 & 10266 & 10938 & 11293 & 14003 & 12511 \\
\hline Itália & 6353 & 7522 & 8414 & 8369 & 8392 & 9963 & 12122 & 12255 & 11938 & 20016 & 18342 \\
\hline Japão & 622 & 691 & 778 & 949 & 1140 & 1460 & 2090 & 2890 & 3150 & 3590 & 3440 \\
\hline Portugal & 875 & 782 & 760 & 929 & 1137 & 1533 & 2144 & 2403 & 2684 & 3579 & 3687 \\
\hline
\end{tabular}

Fonte: International Monetary Fund. Balance of Payments Yearbook. (Vários anos). 
TABELA 4 - RECEITA DO TURISMO RECEPTIVO:

AMÉRICA DO NORTE, EUROPA, ÁSIA

(milhōes de dólares)

\begin{tabular}{|c|c|c|c|c|c|c|}
\hline \multirow{2}{*}{ 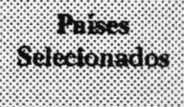 } & \multicolumn{6}{|c|}{ dediar dos unos } \\
\hline & $8.70112 \%$ & $1880,4.89$ & $10 \% 0.109 \pi$ & 16831985 & 1081.1986 & $108+10 \%$ \\
\hline Alemanha & 2373 & 6101 & 10616 & 5080 & 5288 & 7814 \\
\hline Austria & 2396 & 6581 & 13000 & 4796 & 5204 & 9006 \\
\hline Canadá & 1456 & 3859 & 6738 & 3305 & 3317 & 5784 \\
\hline Espanha & 2973 & 9923 & 18797 & 7377 & 7735 & 14106 \\
\hline Estados Unidos & 4006 & 17893 & 46090 & 13152 & 13654 & 28765 \\
\hline França & 2850 & 9245 & 20733 & 7721 & 7391 & 13554 \\
\hline Grécia & 606 & 1463 & 2576 & 1274 & 1445 & 2043 \\
\hline Holanda & 821 & 1997 & 3841 & 1520 & 1599 & 2345 \\
\hline Inglaterra & 2369 & 7375 & 13257 & 5915 & 5991 & 9967 \\
\hline Itália & 3112 & 8118 & 19179 & 8392 & 8169 & 12675 \\
\hline Japão & 260 & 1426 & 3515 & 956 & 940 & 2339 \\
\hline Portugal & 424 & 1055 & 3633 & 942 & 1003 & 2262 \\
\hline
\end{tabular}

Fonte: Dados da Tabela 3
1983 a 1985 e de 1981 a 1986 . Os valores mais elevados das médias 1983 a década de 1980 a 1989 e para o período de 1984 a 1991 para a década de 1980 áno verificada nos últimos três anos da década

de oitenta e o saldo positivo do início dos anos noventa.

Comparando-se os resultados indicados nas Tabelas 2 e 4 verifica-se que somente o México com uma média de 5,7 bilhões de dlares apresenta uma performance acima de países como a Holanda com 3,8 bilhões de dólares, Portugal com 3,6 bilhões de dólares, Japão com 3,5 bilhões de dólares e a Grécia com 2,6 bilhões de dólares. Porém, quando se compara o México com os países líderes vê-se que a sua receita turística representou, por exemplo, no período de 1984 a 1991, $32,3 \%$ da representada pela Itália, 30,2\% da representada pela França, $29,0 \%$ da representada pela Espanha e $14,2 \%$ da representada pelos Estados Unidos.

Estas evidências mostram como os países da América Latina e do Caribe apesar dos excelentes recursos naturais encontram-se numa posição bem inferior a dos países líderes do turismo mundial. Esperase que nesta década tais países, mais estabilizados política e economicamente, possam crescer mais aceleradamente suas atividades turísticas e aproximarem-se do grupo de elite de geração de divisas e, assim, poderem incorporar estes recursos gerados pelo turismo receptivo aos seus processos de crescimento e desenvolvimento econômico e social (MILONE, 1992).

Um trabalho recente datado de 1988 do Instituto Interamericano de Turismo, I.T.T., utilizando informações próprias, analisa o papel do turismo nas economias dos países latino-americanos e do Caribe (ITT, 1988). Deste estudo destacam-se algumas conclusões, a saber:

a) a pouca importância do turismo receptivo desses países quando comparada com a dos países líderes do turismo mundial;

b) a liderança do México relacionada com a proximidade dos Estados Unidos;

c) a situação extremamente frágil do turismo brasileiro.

Em termos da geração de divisas pelas atividades turísticas as Tabelas 5 e 6 elaboradas pelo I. T. T. mostram pelas médias das receitas turísticas nos períodos de 1983 a 1985 e 1981 a 1986 resultados bem próximos dos apresentados para os mesmos países relacionados nas Tabelas 2 e 4, e permitem concluir pela existência de uma 
TABELA 5 - RECEITA DO TURISMO RECEPTIVO INTERNACIONAL PAÍSES DA AMÉRICA LATINA - (Milhões de dólares)

\begin{tabular}{|c|c|c|}
\hline & PAIser & 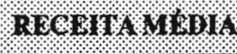 \\
\hline $1^{2}$ & México & $3,045.7$ \\
\hline $2^{2}$ & Bahamas & 756.4 \\
\hline $3^{2}$ & Argentina & 510.5 \\
\hline $4^{2}$ & Jamaica & 362.8 \\
\hline $5^{2}$ & Colômbia & 330.9 \\
\hline $6^{2}$ & R. Dominicana & 319.8 \\
\hline 72 & Venezuela & 312.5 \\
\hline $8^{2}$ & Barbados & 271.1 \\
\hline $9^{2}$ & Peru & 230.0 \\
\hline $10^{\circ}$ & Unuguai & 183.5 \\
\hline $11^{2}$ & Panamá & 179.9 \\
\hline $12^{2}$ & Trinidad e Tobago & 157.5 \\
\hline $13^{2}$ & Chile & 131.6 \\
\hline $14^{2}$ & Equador & 126.5 \\
\hline $15^{2}$ & Costa Rica & 119.4 \\
\hline $16^{2}$ & Brasil & 93.7 \\
\hline $17^{2}$ & Haili & 79.7 \\
\hline $18^{2}$ & Paraguai & 77.2 \\
\hline $19^{\circ}$ & Bolívia & 33.7 \\
\hline $20^{\circ}$ & Honduras & 24.9 \\
\hline $21^{2}$ & El Salvador & 23.5 \\
\hline $22^{2}$ & Guatemala & 14.6 \\
\hline $23^{2}$ & Nicarágua & 13.3 \\
\hline $24^{2}$ & Suriname & 8.5 \\
\hline $25^{2}$ & Guiana & 8.3 \\
\hline
\end{tabular}

Fonte: ITT, 1988.
TABELA 6

RECEITA DO TURISMO RECEPTIVO INTERNACIONAL (Milhões de dólares)

\begin{tabular}{|c|c|c|}
\hline 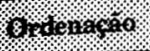 & parises & Recetta Medla \\
\hline $1^{2}$ & U.S.A. & $11,483.0$ \\
\hline $2^{2}$ & Itália & $8,795.3$ \\
\hline $3^{2}$ & França & $7,584.3$ \\
\hline $4^{2}$ & Espanha & $7,580.5$ \\
\hline $5^{2}$ & Inglaterra & $6,222.7$ \\
\hline $6^{2}$ & Alemanha & $5,619.4$ \\
\hline 72 & Austria & $5,116.5$ \\
\hline $8^{2}$ & Suiça & $3,162.6$ \\
\hline $9^{9}$ & Canadá & $2,837.4$ \\
\hline $10^{\circ}$ & México & $2,133.4$ \\
\hline $11^{2}$ & Bélgica-Lux. & $1,678.7$ \\
\hline $12^{2}$ & Holanda & $1,501.3$ \\
\hline $13^{2}$ & Dinamarca & $1,308.2$ \\
\hline $14^{2}$ & Grécia & $1,305.0$ \\
\hline $15^{2}$ & Suécia & $1,122.6$ \\
\hline $16^{\circ}$ & Austrália & $1,071.7$ \\
\hline 172 & Japāo & 976.4 \\
\hline $18^{2}$ & Portugal & 976.0 \\
\hline 198 & Turquia & 912.2 \\
\hline $20^{\circ}$ & Bahamas & 847.2 \\
\hline $21^{2}$ & Noruega & 687.9 \\
\hline 222 & Argentina & 527.1 \\
\hline 232 & Irlanda & 504.2 \\
\hline 242 & Finlândia & 496.2 \\
\hline
\end{tabular}


TABELA 6 (Continuação)

RECEITA DO TURISMO RECEPTIVO INTERNACIONAL (Milhōes de dólares)

\begin{tabular}{|c|c|c|}
\hline 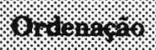 & Harser & Recefta Weada \\
\hline $25^{9}$ & Jamaica & 404.2 \\
\hline $26^{2}$ & R.Dominicana & 380.7 \\
\hline $27^{2}$ & Venezuela & 361.3 \\
\hline $28^{2}$ & Barbados & 284.6 \\
\hline $29^{\circ}$ & N. Zelândia & 274.0 \\
\hline $30^{\circ}$ & Colômbia & 253.7 \\
\hline $31^{2}$ & Peru & 217.1 \\
\hline $32^{2}$ & Panamá & 187.0 \\
\hline $33^{2}$ & Uruguai & 178.3 \\
\hline $34^{\circ}$ & T. e Tobago & 148.8 \\
\hline $35^{2}$ & Costa Rica & 125.3 \\
\hline $36^{2}$ & Equador & 124.3 \\
\hline $37^{2}$ & Chile & 113.4 \\
\hline $38^{2}$ & Haiti & 83.5 \\
\hline $39^{\circ}$ & Paraguai & 83.5 \\
\hline $40^{\circ}$ & Brasil & 56.7 \\
\hline $41^{2}$ & Bolivia & 34.8 \\
\hline $42^{2}$ & Islândia & 34.5 \\
\hline $43^{2}$ & El Salvador & 28.3 \\
\hline $44^{2}$ & Honduras & 23.5 \\
\hline $45^{2}$ & Guiana & 11.7 \\
\hline $46^{\circ}$ & Guatemala & 10.5 \\
\hline $47^{2}$ & Nicarágua & 8.4 \\
\hline $48^{2}$ & Suriname & 4.5 \\
\hline
\end{tabular}

Fonte: ITT, 1988 .

22 elevada correlação entre as séries de dados elaborados pelo I. T. T. e aquelas construídas a partir dos dados dos Balanços de Pagamentos apresentadas nos relatórios anuais publicados pelo Fundo Monetário Internacional.

Assim, as conclusões da análise do I. T. T. podem ser estendidas ao presente estudo para o período de 1970 a 1991 com as ressalvas para o caso brasileiro que será tratado a seguir.

\section{RECEITA DO TURISMO RECEPTIVO DO BRASIL}

Os dados estatísticos sobre as receitas geradas pelo turismo receptivo brasileiro representam uma clara evidência de como estas informações podem estar subestimadas.

Ao analisar-se os dados do Fundo Monetário Internacional que constam das Tabelas 1 e 2 observa-se que o comportamento do turismo receptivo brasileiro em termos de geração de divisas é muito baixo, estando muito próximo dos apresentados para o Paraguai e que somente para os anos de 1989 e 1990 os dados mostram um enorme salto aproximando-se dos valores das Bahamas e abaixo dos vistos para o México. Ao utilizar-se dos dados elaborados pelo ITT e apresentados nas Tabelas 5 e 6 verifica-se que no período de 1981 a 1986, em termos de países latino-americanos e do Caribe, o Brasil situa-se na décima sexta posição e, para o período de 1983 a 1985 incluindo-se os líderes do turismo mundial o Brasil passa a ocupar a quadragésima posição em termos de geração de receita através do turismo receptivo.

O que este fato representa?

Sem dúvida estes resultados indicam que existem erros nas estatísticas do Fundo Monetário Internacional, que são baseadas nos dados fornecidos pelo Banco Central do Brasil para as décadas de setenta e de oitenta. As estatísticas da EMBRATUR para o período de 1975 até o presente procuram corrigir estas distorções e são apresentadas juntamente com as do Banco Central na Tabela 7 (LAGE, 1990).

Quando se compara estes dados com os da Tabela 1 vê-se que o Brasil, pela metodologia de construção da receita do turismo receptivo desenvolvida pela EMBRATUR desde 1975, está situado apenas abaixo do México em termos de geração de divisas turísticas.

$\mathrm{Na}$ Tabela 8 apresentam-se as médias das receitas por anos selecionados, comparando-se as três fontes de informações estatísti- 
TABELA 7 - RECEITA DO TURISMO RECEPTIVO - BRASIL

\begin{tabular}{|c|c|c|}
\hline \multirow{2}{*}{ Nos } & \multicolumn{2}{|c|}{ RHC GIT (Milión de dolares) } \\
\hline & BANCOCAMTI & GMBRA IUP \\
\hline 1970 & 30.1 & - \\
\hline 1971 & 35.9 & - \\
\hline 1972 & 38.3 & - \\
\hline 1973 & 58.5 & - \\
\hline 1974 & 66.7 & - \\
\hline 1975 & 71.2 & 571.8 \\
\hline 1976 & 56.2 & 613.8 \\
\hline 1977 & 55.3 & 700.6 \\
\hline 1978 & 68.1 & 865.8 \\
\hline 1979 & .74 .6 & $1,194.2$ \\
\hline 1980 & 126.0 & $1,794.4$ \\
\hline 1981 & 243.0 & $1,726.7$ \\
\hline 1982 & 65.0 & $1,607.7$ \\
\hline 1983 & 39.2 & $1,532.6$ \\
\hline 1984 & 65.0 & $1,511.5$ \\
\hline 1985 & 65.7 & $1,492.6$ \\
\hline 1986 & - & $1,527.2$ \\
\hline 1987 & - & $1,502.4$ \\
\hline 1988 & - & $1,642.8$ \\
\hline 1989 & - & $1,224.0$ \\
\hline 1990 & - & $1,444.2\left(^{*}\right)$ \\
\hline
\end{tabular}

(*) Estimativa

Fonte: LAGE, 1991; LAGE \& MILONE, 1990.

TABELA 8 - RECEITA DO TURISMO RECEPTIVO DO BRASIL

\begin{tabular}{|c|c|}
\hline ANOS: & Mitdills oros a Nos \\
\hline 1970-1979(1) & 47 \\
\hline 1980-1989(1) & 205 \\
\hline 1990-1991 (i) & 1,383 \\
\hline 1983-1985(1) & 55 \\
\hline $1981-1986(1)$ & 85 \\
\hline 1984-1991 (1) & 434 \\
\hline 1970-1979(2) & 55.5 \\
\hline 1980-1989 (2) & - \\
\hline 1990-1991 (2) & - \\
\hline 1983-1985(2) & 56.6 \\
\hline 1981-1986(2) & - \\
\hline 1984-1991 (2) & - \\
\hline 1970-1979(3) & - \\
\hline 1980-1989 (3) & $1,556.2$ \\
\hline 1990-1991 (3) & - \\
\hline 1983-1985 (3) & $1,512.2$ \\
\hline $1981-1986(3)$ & $1,566.4$ \\
\hline 1984-1991 (3) & - \\
\hline
\end{tabular}

Fonte: (1) Dados das Tabelas 1 e 2 - International Monetary Fund (2) Dados da Tabela 7 - Banco Central do Brasil.

(3) Dados da Tabela 7 - Embratur. 
cas; e, verifica-se pelos dados da EMBRATUR que o turismo receptivo brasileiro representa uma atividade importante para a economia do país a partir da segunda metade dos anos setenta até o presente, com valores acima de 1,5 bilhões de dólares por ano a partir de 1980. Estes resultados colocam o Brasil em segundo lugar em termos de receitas criadas pelas atividades do turismo receptivo no continente latino-americano.

Estas discrepâncias existentes nas estatísticas brasileiras indicam com clareza a necessidade dos países em geral investirem mais e mais recursos para a elaboração de informações empíricas corretas. E, a concretização deste objetivo irá permitir a esses países conhecerem melhor as suas próprias realidades e, como resultante, elaborarem políticas específicas e eficientes. Desta maneira, concluindo, os países da América Latina e do Caribe poderão num futuro próximo elaborar e implementar programas de criação e expansão de suas atividades de turismo receptivo de uma forma mais racional e, como conseqüência, obter recursos financeiros através da entrada de divisas que irão contribuir de forma positiva para os seus processos de crescimento e desenvolvimento econômico e social.

\section{REFERÊNCIAS BIBLIOGRÁFICAS}

FOOTE, D. L. \& HAWKINS, D. E. 1990. Turismo Venezuela-Oportunidades de Inversión, v. 1, 1990-1991, Caracas, Oct. p. 21.

ITT. Instituto Interamericano de Turismo. 1988. El turismo en la economia de los paises latinoamericanos. Washington, p. 4-14. Série Investigaciones Periodicas, n. 2.

LAGE, B. H. G. 1989. Contradiçōes - Conta turismo brasileira. Revista de Comunicações e Artes. São Paulo, v. 14, n. 20, abril, p. 45-50.

LAGE, B. H. G. \& MILONE, P. C. 1990. Economia do turismo. São Paulo, Papirus, p. 84-104.

MILONE, P. C. 1992. Crescimento e desenvolvimento económico. Manual de Economia. São Paulo, Saraiva, 2a. edição, p. 467-481.

UNITED NATIONS. Economic Comission for Latin America and the Caribbean ECLAC. 1990. Preliminary overview of the economy of Latin America and the Caribbean, Chile, Dec.

WILLIAMS, A. W. \& GARETT, S. 1988. Tourism and economic development. London, Belhaven Press, p. 1-10. 